\section{ARTIGO}

Recebido em: $29 / 08 / 2018$

Aceito em: $22 / 11 / 2018$

\title{
ESTRUTURAS DE REPRESENTAÇÃO DA INFORMAÇÃO E SEU APOIO À ARQUITETURA DA INFORMAÇÃO NA WEB: UM OLHAR SOBRE VOCABULÁRIOS CONTROLADOS, TESAUROS E METADADOS
}

\author{
STRUCTURES OF THE REPRESENTATION OF INFORMATION AND ITS \\ SUPPORT OF INFORMATION ARCHITECTURE ON THE WEB: A LOOK AT \\ CONTROLLED VOCABULARIES, THESAURI AND METADATA
}

\author{
Luciana DUMER (ludumer2016@gmail.com)* \\ Marckson Roberto Ferreira de SOUSA (marckson.dci.ufpb@gmail.com)** \\ Maria Elizabeth Baltar Carneiro de ALBUQUERQUE (ebaltar2007@gmail.com) \\ * Mestranda do Programa de Pós-graduação em Ciência da Informação (PPGCI/UFPB). \\ ** Doutor em Engenharia Elétrica na área de Processamento da Informação pela Universidade \\ Federal da Paraíba (UFPB). Professor do Programa de Pós-Graduação em Ciência da Informação \\ (PPGCI/UFPB) e Programa de Pós-Graduação em Gestão nas Organizações Aprendentes \\ (MPGOA/UFPB) \\ ***Professora do Programa de Pós-graduação em Ciência da Informação (PPGCI/UFPB).
}

\begin{abstract}
Resumo
Na perspectiva da sociedade contemporânea, com as inovações tecnológicas e a explosão informacional, uma grande mudança ocorreu nos processos de produção, armazenamento, recuperação e disseminação de informações em âmbito mundial. Com a internet e a web, a informação a cada dia ganha mais destaque e valor. Com isso, novas preocupações surgem concernentes à Representação da Informação em ambientes digitais. Despontam no cenário da Ciência da Informação e em outras áreas, o desafio de organizar e facilitar o uso da informação relevante em meio a uma infinita gama de conteúdos lançados na internet diariamente. Com o presente estudo, por meio de uma revisão bibliográfica, foi possível conhecer características das estruturas de representação da informação e de sua aplicação na web. Os resultados apontaram que as técnicas de controles de vocabulários, os tesauros e os metadados, já comumente usados por profissionais da informação, passaram a fazer parte da arquitetura de websites, contribuindo para a organização da informação em ambientes digitais.
\end{abstract}

Palavras-chave: Organização da informação. Representação da informação. Ambientes digitais.

\begin{abstract}
From the perspective of contemporary society with technological innovations and the informational explosion, a great change occurred in the processes of production, storage, retrieval and dissemination of information worldwide. With the internet and the web the information every day gains more prominence and value. With this, new concerns arise concerning Representation of Information in digital environments. The challenge of organizing and facilitating the use of relevant information in the midst of an infinite range of content launched on the internet on a daily basis is emerging in the Information Science scene and in other areas. With the present study, through a bibliographic review, it was possible to know characteristics of the information representation structures and their application on the web. The results showed that the techniques of vocabulary controls, thesauri and metadata, already commonly used by information professionals have become part of the architecture of websites contributing to the organization of information in digital environments.
\end{abstract}

Keywords: Organization of information. Representation of information. Digital environments.

v. 24, n. $54,2019$. p. $38-51$

ISSN 1518-2924

Esta obra está licenciada sob uma Licença Creative Commons. 


\section{INTRODUÇÃO}

A partir de meados do Século XX, com o fim da Segunda Guerra (1939-1945), o advento tecnológico deu início a uma explosão informacional que, com o passar dos anos tomou grandes proporções e continua fortemente presente na sociedade contemporânea. Com a chegada da era digital e da web, uma grande mudança ocorreu no que tange aos processos de produção, armazenamento, recuperação e disseminação de informações em âmbito mundial. Nesse contexto, a Ciência da Informação (CI) vem atuando como uma área do conhecimento marcada pela interdisciplinaridade com diversas áreas, tais como: a Biblioteconomia, a Comunicação, a Ciência da Computação e muitas outras.

Atualmente, nos componentes curriculares de cursos de Pós-graduação em $\mathrm{CI}$, se faz presente a temática de estudos em Arquitetura da Informação (AI), uma vez que estas são duas áreas cujos princípios fundamentais muito se relacionam. Ao considerar as relações epistemológicas da Arquitetura da Informação com a CI, os autores Silva, Dias e Sousa (2014, p. 236), ressaltam que "ambas estão preocupadas em trabalhar a informação de modo a torná-la acessível e usável por todos que dela necessitem". Silva e Souza (2017) consideram que a Arquitetura da Informação (AI) pode se consolidar no campo da CI como domínio convergente uma vez que a AI "se dedica a reflexões sobre os processos de organização e recuperação da informação, integrando conteúdos, tecnologias e usuários" (SILVA; SOUZA, 2017, p. 173).

Um dos principais motivos para o desenvolvimento da CI enquanto campo científico, foi a necessidade de organização e recuperação eficiente da informação de qualidade em meio ao problema da explosão informacional. Sendo assim, os processos de Recuperação da Informação sempre fizeram parte das problemáticas de pesquisas em CI. Além disso, as proximidades da CI com as áreas correlatas como a Biblioteconomia e Documentação, trouxeram consigo estudos acerca das estruturas utilizadas para a representação da informação na web, tais como os vocabulários controlados, os tesauros e os metadados. Estas estruturas objetivam contribuir para uma recuperação eficaz e eficiente da informação em meio digital e foram especialmente destacadas por Louis Rosenfeld, Peter Morville e Jorge Arango, pesquisadores no campo da AI.

A presente pesquisa, através de uma revisão bibliográfica, objetivou identificar características destas três estruturas de representação da informação e por meio de alguns exemplos, entender de que forma as mesmas estão sendo aplicadas em websites hoje, na internet. Os autores Rosenfeld, Morville e Arango (2015), apontaram que tais estruturas de representação da informação - vocabulários controlados, tesauros e metadados - servem de apoio para os sistemas que compõem a Arquitetura da Informação (AI), que são: sistema de organização, sistema de navegação, sistema de rotulação e sistema de busca. Sistemas estes que, segundo os mesmos autores, permeiam os princípios fundamentais para a Arquitetura da Informação em websites.

\section{SOBRE ARQUITETURA DA INFORMAÇÃO E SEUS SISTEMAS}

A Arquitetura da Informação (AI) em ambientes digitais foi abordada pela primeira vez na década de 90, com a chegada da Web. Neste momento, despontava no cenário mundial o comércio eletrônico e as empresas passaram a adotar a internet como principal meio para a divulgação de seus negócios com o uso dos websites. No ano de 1994, Peter Morville e Louis Rosenfeld foram os primeiros a aplicar a Arquitetura da Informação no design de websites e posteriormente, lançaram o livro Information Architecture for the World Wide Web, considerado best seller da área (SILVA; DIAS; SOUSA, 2014, p. 232), que chegou em sua $4^{\mathrm{a}}$ edição no ano de 2015.

Para Rosenfeld, Morville e Arango $(2015$, p. 24) existem várias definições para explicar o que é a Arquitetura da Informação: a) 0 design estrutural de ambientes de informação compartilhados; b) A síntese dos sistemas de organização, rotulagem, pesquisa e navegação dentro dos ecossistemas digitais, físicos e de canais cruzados; c) A arte e a ciência de moldar produtos e experiências de informação para suportar a usabilidade, a capacidade de encontrar e a compreensão; d) Uma disciplina emergente e uma comunidade de práticas focada em trazer princípios de design e arquitetura para a paisagem digital.

Os autores apresentam os componentes da Arquitetura da Informação em quatro categorias de sistemas, sendo:

- Sistema de Organização: podem ser exatos quando incluem agrupamentos alfabéticos, cronológicos e geográficos; ou ambíguos quando incluem grupos tópicos, baseados em tarefas, baseados em público, metafóricos e híbridos.

- Sistema de Rotulação: os rótulos podem ser textuais ou icônicos.

- Sistema de Navegação: podem ser de vários tipos, mas os três mais comuns são os Globais, que são destinados a estar presentes em todas as páginas ou telas 
no ambiente de informações; os Locais, que complementam os globais e permitem que os usuários explorem a área imediata onde estão; e os Contextuais que ocorrem no contexto do conteúdo que está sendo apresentado no ambiente e apoiam a aprendizagem associativa ao permitir que os usuários explorem as relações entre os itens.

- Sistema de Busca: embora pareça ser simples, envolve vários fatores importantes tais como: o que procurar, o que recuperar e como apresentar os resultados, sendo que estes fatores precisam se juntar na interface de busca (ROSENFELD; MORVILLE; ARANGO, 2015).

A aplicação dos princípios da Arquitetura da Informação com o apoio das Estruturas de Representação da Informação, visam trazer facilidades para os usuários, de modo que estes possam encontrar as informações que desejam com maior rapidez.

\section{SOBRE A REPRESENTAÇÃO DA INFORMAÇÃO}

Nos dias atuais, a informação está sendo produzida em escalas sem precedentes e de diversas formas. Temos presenciado, muitas vezes, o mesmo conteúdo informacional aparecendo em diferentes tipos de formatos e suportes, que vão desde o impresso ou físico, até o digital ou eletrônico, isto é o que vem acontecendo, por exemplo, no caso dos jornais e livros. No entanto, até mesmo a informação que insiste em manter o seu conteúdo completo apenas em suportes físicos ou apenas em formato impresso, necessita ser representada em sistemas de informação digitais disponíveis em websites. Tal representação na web pode ter como objetivo tanto a recuperação da informação em si, como também a sua divulgação, tendo sempre como foco principal a satisfação das necessidades dos usuários daquela informação. Desta forma, é possível afirmar que a representação da informação na web está alcançando um grau de importância, na sociedade contemporânea, como nunca alcançou em nenhuma outra época.

Sobre a preocupação e a importância da construção e disseminação da informação, Ferreira e Albuquerque (2013, p. 18), argumentam que tais preocupações resultam da "importância atribuída ao conhecimento como uma forma de vantagem competitiva" nos dias atuais.

As grandes quantidades de informações lançadas em sistemas de recuperação, dificilmente contribuirão para gerar novos conhecimentos se estiverem desorganizadas ou sem nenhum tipo de tratamento ou cuidado com sua representação. Sousa (2012), explica que essa infinidade de informações disponíveis em ambientes digitais, que deveria ser um fator positivo na sociedade, pode, na verdade, causar "barreiras" no acesso, uma vez que, nem sempre a informação é disponibilizada de forma apropriada nos websites e assim, muitas vezes, não se alcança o objetivo principal, já mencionado, que é atender às necessidades dos usuários. Sousa (2012, p. 68, grifo nosso) acrescenta que “[...] os usuários nem sempre conseguem encontrar o que desejam, seja pelo fato dos sistemas de busca não realizarem uma recuperação de forma satisfatória, seja porque ela não foi concebida para o usuário através de uma representação adequada".

$\mathrm{Na}$ atividade de representação realizada pelos profissionais da informação, são apresentadas aos usuários duas possibilidades de acesso à informação nos sistemas, conforme mencionado por Gomes e Santos (2013): a) através da representação descritiva, onde ocorre a descrição dos dados físicos do material, permitindo a realização de buscas por autor, por título, por tipo de material, etc. e b) através da representação temática, onde ocorre a descrição do conteúdo, ou seja, dos assuntos contidos no material, o que permitirá ao usuário realizar buscas por assuntos de interesse. Catarino e Souza (2012, p. 84) também distinguiram a representação descritiva e a representação temática ao afirmarem que,

[...] A descritiva representa as características específicas do documento que permitem sua individualização e também define e padroniza os pontos de acesso responsáveis pela busca e recuperação da informação e pela reunião de documentos semelhantes. A temática detém-se na atribuição de assuntos aos documentos a partir da classificação bibliográfica, da indexação e da elaboração de resumos, facilitando a recuperação de materiais relevantes que dizem respeito a temas semelhantes.

Apesar de terem sido originalmente pensadas para a organização de coleções em bibliotecas físicas, as representações temática e descritiva são totalmente aplicáveis ao ambiente digital. (SILVA; NEVES, 2013; CATARINO; CERVANTES; ANDRADE, 2015). Nesse sentido, Maia (2015, p. 84) afirma que "um árduo processo de representação, de descrição física e temática, de escolha de termos, de controle de vocabulário, de construção de índice e de arranjo da categorização terminológica (classificação), envolve a precisão da informação." Convém destacar, portanto, que existe um importante trabalho de organização e representação 
da informação que é feito nos bastidores dos sistemas digitais e que passa muitas vezes despercebido pelos usuários que utilizam a interface dos sistemas de busca.

\section{PERCURSO METODOLÓGICO}

Quanto às fontes, o presente estudo revela-se um estudo bibliográfico partindo da visão de Rosenfeld, Morville e Arango (2015) acerca das características de três estruturas de representação da informação e sua utilização em websites, sendo: a) os vocabulários controlados; b) os tesauros, criados a partir dos esquemas de classificação hierárquicos e facetados; e c) os metadados, utilizados tanto para representação temática como também para a descritiva. Nessa perspectiva, foram consultadas bibliografias das áreas de CI e AI, nacionais e estrangeiras conforme o Quadro 1, a seguir:

Quadro 1: Bibliografias consultadas sobre Vocabulários controlados, Tesauros e Metadados.

\begin{tabular}{|c|c|c|c|}
\hline Referência Bibliográfica & $\begin{array}{c}\text { Tipo de } \\
\text { publicação }\end{array}$ & Ano & $\begin{array}{l}\text { Idioma da } \\
\text { publicaçãa }\end{array}$ \\
\hline $\begin{array}{l}\text { ASSUMPÇÃO, Fabrício Silva; SANTOS, Plácida Leopoldina Ventura Amorim da Costa. } \\
\text { Metadata Authority Description Schema (MADS): uma alternativa à utilização do formato } \\
\text { MARC } 21 \text { para dados de autoridade. Inf. Inf., Londrina, v. 18, n.1, p. 106-126, jan./abr. } 2013\end{array}$ & $\begin{array}{l}\text { Artigo de } \\
\text { periódico }\end{array}$ & 2013 & Português \\
\hline $\begin{array}{l}\text { ASSUMPÇ̃̃̃O, Fabrício Silva; SANTOS, Plácida Leopoldina Ventura Amorim da Costa. } \\
\text { Representação no domínio bibliográfico: um olhar sobre os Formatos MARC 21. Perspectivas } \\
\text { em Ciência da Informação, v.20, n.1, p.54-74, jan./mar. } 2015\end{array}$ & $\begin{array}{l}\text { Artigo de } \\
\text { periódico }\end{array}$ & 2015 & Português \\
\hline $\begin{array}{l}\text { CAMPOS, Maria Luiza de Almeida. Linguagem Documentária: teorias que fundamentam sua } \\
\text { elaboração. Rio de Janeiro: EdUFF, } 2001 .\end{array}$ & Livro & 2001 & Português \\
\hline $\begin{array}{l}\text { CASTRO, Fabiano Ferreira de; SANTOS, Plácida Leopoldina Ventura Amorim da Costa. } \\
\text { Elementos de interoperabilidade na perspectiva da catalogação descritiva. Inf. \& Soc.: Est., } \\
\text { João Pessoa, v.24, n.3, p. 13-25, set./dez. } 2014\end{array}$ & $\begin{array}{l}\text { Artigo de } \\
\text { periódico }\end{array}$ & 2014 & Português \\
\hline $\begin{array}{l}\text { CASTRO, Fabiano Ferreira de; SANTOS, Plácida Leopoldina Ventura Amorim da Costa. Os } \\
\text { metadados como instrumentos tecnológicos na padronização e potencialização dos recursos } \\
\text { informacionais no âmbito das bibliotecas digitais na era da web semântica. Inf. \& Soc.: Est., } \\
\text { João Pessoa, v.17, n.2, p.13-19, maio/ago. } 2007\end{array}$ & $\begin{array}{l}\text { Artigo de } \\
\text { periódico }\end{array}$ & 2007 & Português \\
\hline $\begin{array}{l}\text { CURRÁS, Emilia. Ontologies, Taxonomies and Thesauri in Systems Science and Systematics. } \\
\text { Oxford: Chandos Publishing, 2010.133 p. }\end{array}$ & Livro & 2010 & Inglês \\
\hline $\begin{array}{l}\text { DODEBEI, Vera Lucia Doyle. Tesauro: linguagem de representação da memória } \\
\text { documentária. Rio de Janeiro: Interciência, 2002.120 p. }\end{array}$ & Livro & 2002 & Português \\
\hline $\begin{array}{l}\text { DUARTE, Elizabeth Andrade. Classificação facetada: um olhar sobre a construção de } \\
\text { estruturas semânticas. Revista Digital de Biblioteconomia e Ciência da Informação, Campinas, } \\
\text { v.7, n. 2, p. 46-58, jan./jun. } 2010 \text {. }\end{array}$ & $\begin{array}{l}\text { Artigo de } \\
\text { periódico }\end{array}$ & 2010 & Português \\
\hline $\begin{array}{l}\text { GARRET, Jesse James. The elements of user experience: user-centered design for the web and } \\
\text { beyond. 2. ed. Berkeley, CA: News Riders, } 2011 .\end{array}$ & Livro & 2011 & Inglês \\
\hline $\begin{array}{l}\text { GOMES, Hagar Espanha (Coord.). Instituto brasileiro de informação em ciência e tecnologia - } \\
\text { IBICT. Diretrizes para elaboração de tesauros monolíngues. Brasília: IBICT, } 1984.70 \text { p. }\end{array}$ & Livro & 1984 & Português \\
\hline $\begin{array}{l}\text { GRINGS, Luciana. Controle de autoridades na Biblioteca Nacional do Brasil: breve histórico e } \\
\text { práticas atuais. Revista Brasileira de Biblioteconomia e Documentação. São Paulo, v. 11, n. 2, p. } \\
\text { 139-154, jul./dez. 2015. }\end{array}$ & $\begin{array}{l}\text { Artigo de } \\
\text { periódico }\end{array}$ & 2015 & Português \\
\hline $\begin{array}{l}\text { LANCASTER, Frederick Wilfrid. Construção e uso de tesauros: curso condensado. Brasília: } \\
\text { IBICT, } 1987 .\end{array}$ & Livro & 1987 & Português \\
\hline $\begin{array}{l}\text { LIMA, Fábio Rogério Batista; SANTOS, Plácida Leopoldina V. A. C.; SANTARÉM SEGUNDO, José } \\
\text { Eduardo. Padrão de metadados no domínio museológico. Perspectivas em Ciência da } \\
\text { Informação, v.21, n.3, p.50-69, jul./set. } 2016 .\end{array}$ & $\begin{array}{l}\text { Artigo de } \\
\text { periódico }\end{array}$ & 2016 & Português \\
\hline $\begin{array}{l}\text { LIMA, Gercina Ângela de; MACULAN, Benildes Coura Moreira dos Santos. Estudo comparativo } \\
\text { das estruturas semânticas em diferentes sistemas de organização do conhecimento. Ciência } \\
\text { da Informação, [S.I.], v. 46, n. 1, dez. } 2017 \text {. }\end{array}$ & $\begin{array}{l}\text { Artigo de } \\
\text { periódico }\end{array}$ & 2017 & Português \\
\hline $\begin{array}{l}\text { ROSENFELD, Louis; MORVILLE, Peter; ARANGO, Jorge. Information architecture for the web } \\
\text { and beyond. 4. ed. Sebastopol, CA: O'Relly Media, } 2015 \text {. }\end{array}$ & Livro & 2015 & Inglês \\
\hline $\begin{array}{l}\text { UNESCO. Diretrizes para o estabelecimento e desenvolvimento de tesauros monolíngues. [2a ed. } \\
\text { rev. por Derek Austin e Peter Dale]; traduzido por Bianca Amaro de Meto e revisto por Lígia } \\
\text { Maria Café de Miranda. Brasília: IBICT/SENAI, 1993. } 86 \text { p. }\end{array}$ & Livro & 1993 & Português \\
\hline
\end{tabular}

\section{Fonte: Elaboração própria.}

As preocupações com as estruturas de representação para a organização da informação visando facilitar o seu acesso, uso e disseminação, já vinham sendo uma preocupação de profissionais da informação, principalmente dos bibliotecários, muito antes de existir a internet e a web. Com isso, 
considera-se que o presente estudo possui natureza descritiva e abordagem qualitativa porque não pretende quantificar dados, mas sim, verificar características das estruturas de representação da informação, há muito já conhecidas pelos bibliotecários, e identificar como elas se aplicam hoje, em websites no ambiente digital. De acordo com Sampieri, Collado e Lucio (2006, p. 112) "os estudos descritivos servem para analisar como é e como se manifesta um fenômeno e seus componentes".

Assim, o estudo foi desenvolvido em duas etapas principais, sendo: 1. Revisão bibliográfica sobre as características das estruturas de representação da informação mencionadas por Rosenfeld, Morville e Arango (2015): vocabulários controlados, tesauros e metadados; e 2. Identificação da aplicação dessas estruturas de representação da informação em alguns websites escolhidos de forma aleatória, na internet.

\section{ESTRUTURAS DE REPRESENTAÇÃO DA INFORMAÇÃO: OS VOCABULÁRIOS CONTROLADOS E OS TESAUROS}

Os vocabulários controlados são instrumentos fundamentais para a organização e representação temática de conteúdos em diversas áreas do conhecimento, esse controle contribui de forma efetiva para o armazenamento e a recuperação das informações em sistemas de recuperação digitais. Garret (2011), destaca os vocabulários controlados como sendo a ferramenta que impõe consistência aos conteúdos digitais. Na construção de um site é preciso falar a linguagem do usuário, definindo os conceitos e as terminologias que serão utilizadas, de modo a facilitar a compreensão da estrutura do ambiente bem como a recuperação eficiente de informações. Os vocabulários controlados são de diferentes tipos, desde os mais simples até os mais complexos, conforme retratado na Figura 1, a seguir:

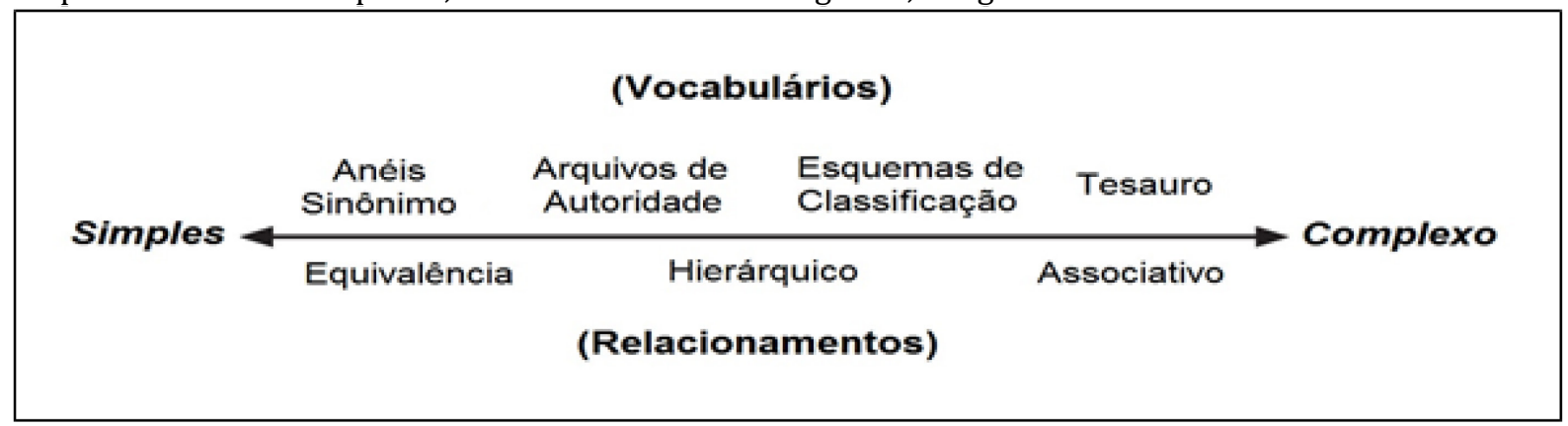

Figura 1: Tipos de vocabulários controlados

Fonte: Rosenfeld, Morville e Arango (2015, p. 271, tradução nossa).

Conforme pode ser observado na Figura 1, Rosenfeld, Morville e Arango (2015) abordaram a importância dos vocabulários controlados desde os mais simples, como um agrupamento de sinônimos que abrange os relacionamentos de termos equivalentes, passando pelos arquivos de autoridade e esquemas de classificação, onde os relacionamentos avançam para níveis hierárquicos e chegando ao mais complexo que é o tesauro. Um tesauro compreende todas as formas de relacionamentos entre os termos, incluindo os associativos.

\subsection{OS ANÉIS SINÔNIMOS}

Mesmo sendo considerado um controle simples, os anéis sinônimos fazem grande diferença para os resultados de busca e podem ajudar muito os usuários. Comumente, pode-se observar que usuários diferentes buscam o mesmo produto ou assunto digitando termos diferentes na pesquisa, por exemplo, enquanto uma pessoa busca na internet por geladeira uma outra pode estar buscando por refrigerador, podendo assim ocasionar ambiguidades e diferentes resultados na recuperação de informações. 0 estabelecimento de termos equivalentes com o uso dos anéis sinônimos pode solucionar esse problema. Além disso, também podem direcionar o usuário quando este digita o termo errado (ROSENFELD; MORVILLE; ARANGO, 2015).

Atualmente, é possível notar que muitos ambientes digitais e websites estão se atentando para o uso destes controles de vocabulário, um exemplo pode ser observado na Figura 2, onde lançou-se, no site de busca Google, o nome pessoal errado Melville Dewei e o site direcionou os resultados da pesquisa para o nome correto que é Melvil Dewey. 


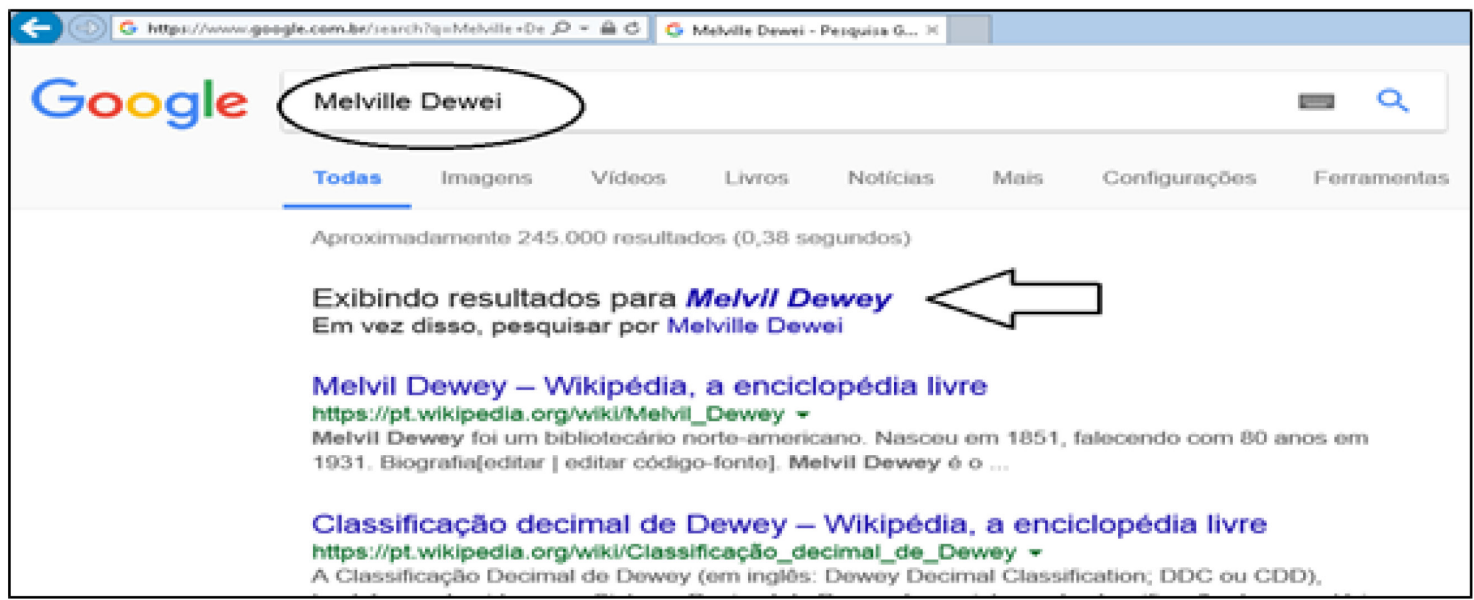

Figura 2 - Resultados de busca com relações de equivalência entre termos.

Fonte: Disponível em: <http://google.com.br>. Acesso em: 03 ago. 2017.

Outro exemplo pode ser observado no catálogo on-line da Biblioteca Nacional do Brasil (BN) em sua página na $w e b$, onde é possível notar o estabelecimento da relação de equivalência entre termos pelos idiomas inglês/português, conforme demonstrado na Figura 3, a seguir.

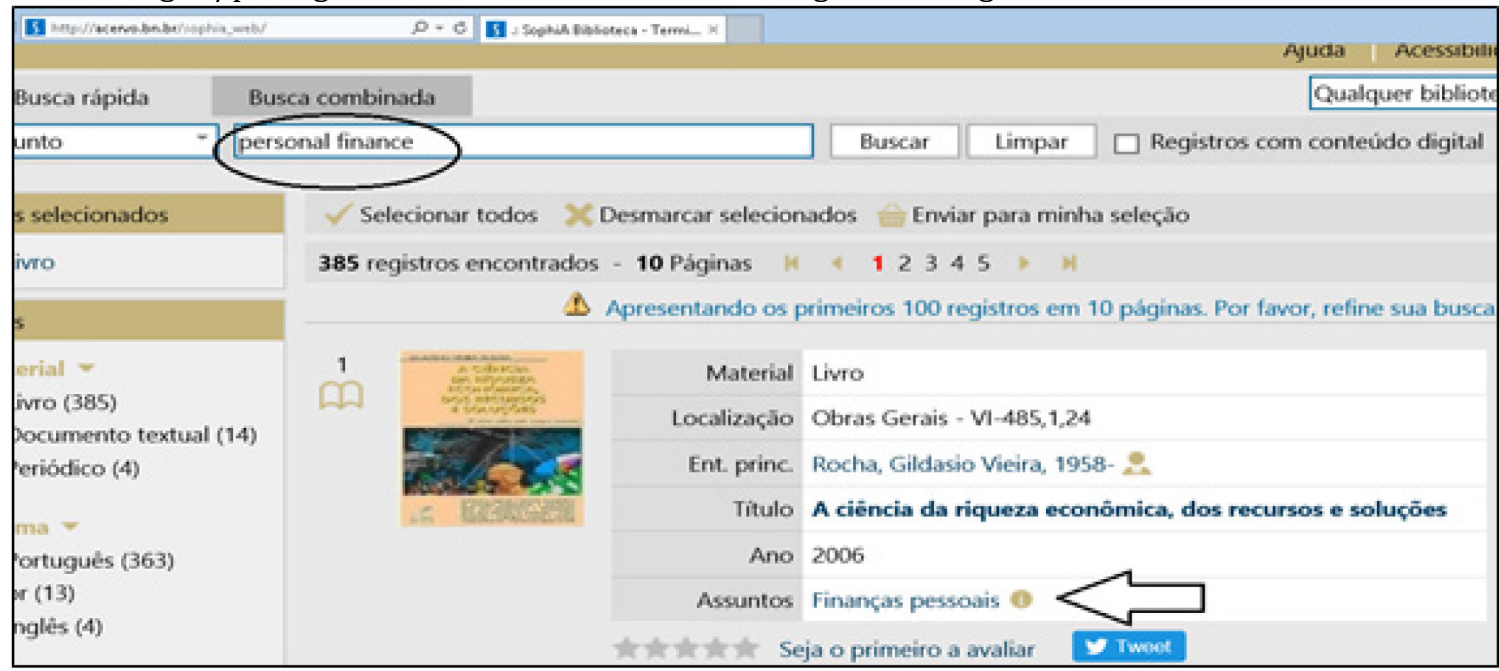

Figura 3 - Busca pelo assunto em inglês personal finance na página da Biblioteca Nacional.

Fonte: Disponível em: <http://acervo.bn.br/sophia web>. Acesso em: 03 ago. 2017.

Conforme mostra a Figura 3, ao realizar a pesquisa por assunto digitando o termo em inglês personal finance, o sistema da BN recuperou os registros de materiais cuja descrição temática possui o termo Finanças pessoais em português. Para tornar isso possível, as bibliotecas lançam mão dos arquivos para controle de autoridade, onde são estabelecidos os relacionamentos entre os termos.

\subsection{OS ARQUIVOS DE AUTORIDADE}

$\mathrm{Na}$ prática, os arquivos de autoridade geralmente incluem termos preferenciais e variantes. Em outras palavras, os arquivos de autoridade são anéis sinônimos em que um termo foi definido como o termo preferido ou valor aceitável (ROSENFELD; MORVILLE; ARANGO, 2015). Os registros de autoridades frequentemente são utilizados em catálogos de bibliotecas para a padronização de cabeçalhos de assuntos, de nomes geográficos, de nomes pessoais, nomes de entidades coletivas, títulos de eventos e títulos uniformes.

Diante da diversidade de pontos de acesso para uma entidade, um usuário do catálogo com o conhecimento de apenas um dos nomes pode não encontrar todos os recursos informacionais associados à entidade por ele desejada, por exemplo, todos os livros de um determinado autor. Desse modo, faz-se necessário reunir e controlar os pontos de acesso, assegurando que tal usuário encontre todos os recursos associados à entidade desejada ao realizar uma única busca. Dessa necessidade surge o conceito de controle de autoridade (ASSUMPÇÃO; SANTOS, 2013, p. 109). 
Assim, com os registros de autoridades, a biblioteca escolhe um termo preferido para representar os termos tópicos/assuntos, nomes pessoais, eventos, nomes geográficos e outros. Junto ao termo preferencial, são atreladas as demais variações do nome, através da inclusão de remissivas. Com isso, o usuário poderá realizar a pesquisa digitando diferentes formas de nome e o sistema responderá recuperando todas as variações em uma só busca. Algumas instituições como a Biblioteca Nacional do Brasil e a Library of Congress dos Estados Unidos disponibilizam, para consulta, os seus registros de autoridades em catálogos on-line. A Figura 4, a seguir, mostra como a Library of Congress cadastrou o nome pessoal do músico brasileiro Luiz Gonzaga e as suas variações.

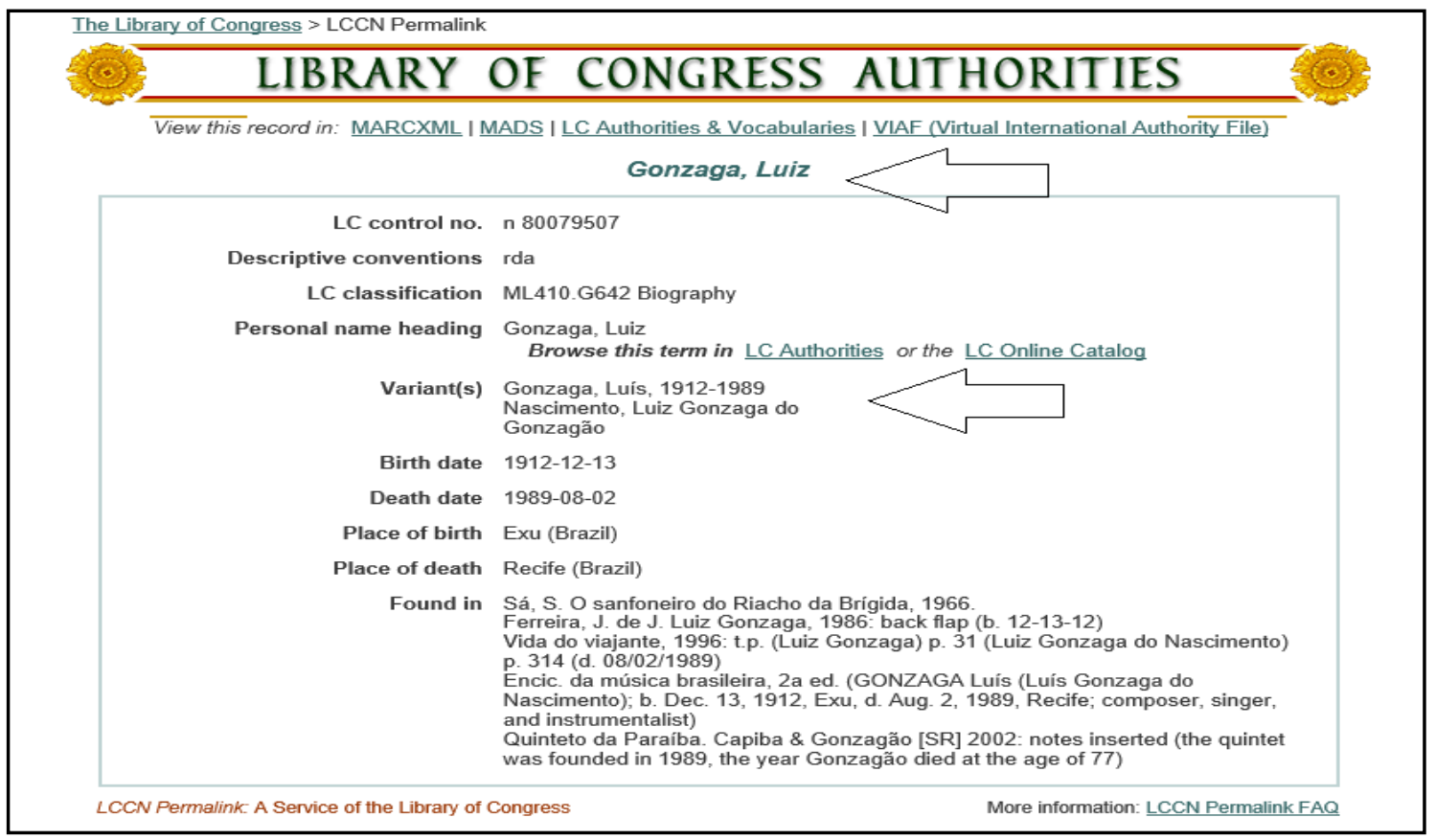

Figura 4: Registro do nome pessoal Luiz Gonzaga, no catálogo de autoridades da LC.

Fonte: <https://lccn.loc.gov/n80079507>. Acesso em: 06 ago. 2017.

Esses registros de autoridade, geralmente são feitos internamente, nos sistemas, por bibliotecários treinados. Na interface de busca do catálogo on-line de materiais da biblioteca, eles aparecem para os usuários como pontos de acesso. A partir desses pontos de acesso, com o uso de hipertexto, é possível direcionar as pesquisas do usuário a outros pontos dentro do catálogo on-line. Clicando no nome de um determinado autor, por exemplo, o sistema poderá direcionar o usuário para outros materiais existentes no catálogo, agrupados para o mesmo autor.

0 mesmo poderá ocorrer com outros tipos de pontos de acesso, tais como os cabeçalhos de assuntos, uma vez que o assunto controlado com o cadastro de autoridade-assunto também permite o agrupamento de materiais por assunto/tema. Dessa forma, ao selecionar um assunto que aparece na descrição de um item, o usuário poderá ser direcionado para outros materiais unidos naquele mesmo tópico.

A figura 5, a seguir, demonstra como aparecem esses pontos de acesso, em um registro de livro, na página de buscas do catálogo on-line da $\mathrm{BN}$.

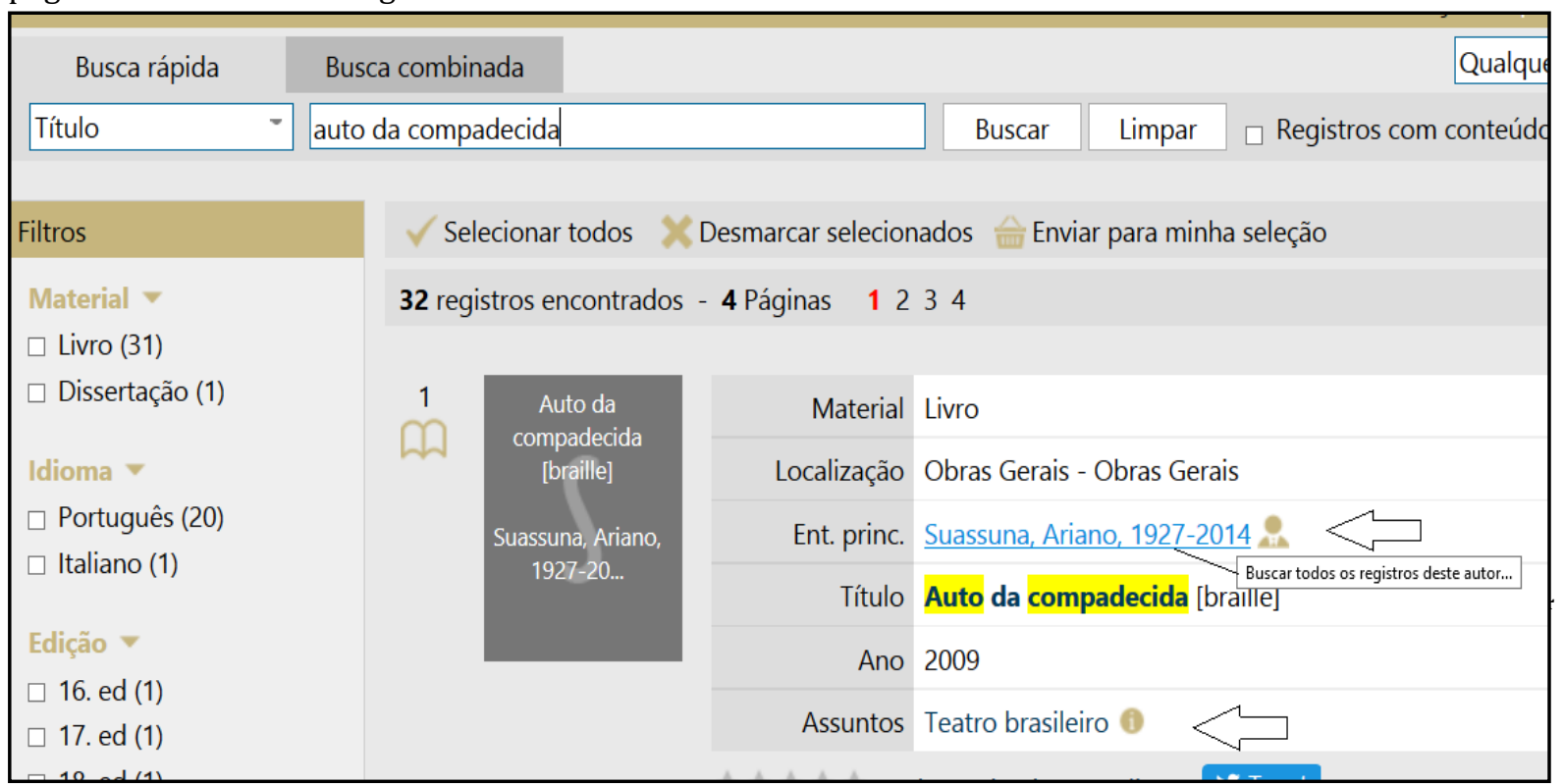


Figura 5 - Resultado de Busca rápida por Título no catálogo on-line da Biblioteca Nacional.

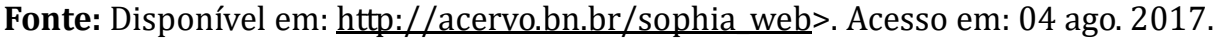

Conforme demonstrado na Figura 5, foi realizada uma busca rápida pelo título digitando-se a expressão Auto da Compadecida no catálogo on-line da BN. O Sistema recuperou 32 (trinta e dois) registros e trouxe uma lista com uma prévia das representações descritiva e temática de cada item encontrado. Logo no primeiro registro, demonstrado na Figura 5, é possível observar dois tipos de autoridades controladas (pontos de acesso), em formato de hiperlink, que são: uma com o nome do autor e datas de nascimento e morte ligadas ao nome: Suassuna, Ariano, 1927-2014; e outra com o assunto temático do material: Teatro brasileiro. Nesse caso, se o usuário desejar, partindo desse registro de livro, ele poderá navegar pelos outros títulos deste mesmo autor no catálogo, para isso, bastaria clicar em cima do nome do autor. Por outro lado, se o usuário desejar ver outros materiais que contemplem o mesmo assunto deste material, bastaria clicar no termo Teatro brasileiro, para ser transportado dentro do catálogo.

0 controle de autoridades é uma das atividades indispensáveis para o sucesso do controle bibliográfico, um dos objetivos máximos da Biblioteconomia em nível mundial. É através do controle de autoridades, em geral exercido pelo Centro Bibliográfico Nacional de cada país, que os registros bibliográficos tornam-se mais confiáveis. Além disso, a centralização do controle de autoridades permite o intercâmbio de dados, economizando recursos das bibliotecas integrantes do sistema tradicionalmente encabeçado por aquele Centro. É comum que o Centro Bibliográfico Nacional confunda-se com a Biblioteca Nacional de cada país, mas não necessariamente a Biblioteca ocupa-se daquela tarefa. No caso dos Estados Unidos, por exemplo, é a Biblioteca do Congresso (Library of Congress-LC) que se encarrega do controle das autoridades utilizadas nas bibliotecas americanas, e baseia o controle de várias outras bibliotecas ao redor do mundo; por exemplo, a do Brasil (GRINGS, 2015, p. 144).

As bibliotecas realizam esse controle bibliográfico utilizando os padrões de metadados para arquivos de autoridades. Mas, antes de discorrer sobre os metadados, é importante destacar outros recursos de representação da informação e controle de vocabulários, encontrados nas arquiteturas de ambientes digitais, que são: os esquemas de classificação hierárquicos e/ou facetados e também os Tesauros.

\subsection{OS ESQUEMAS DE CLASSIFICAÇÃO}

A organização da informação por meio de esquemas de classificação foi pensada e adotada por profissionais da informação antes da era digital. Voltando um pouco na história, pode-se observar, por exemplo, o trabalho do bibliotecário norte-americano Melvil Dewey (1851-1931), criador do Sistema de Classificação Decimal de Dewey (CDD) que teve sua primeira edição no ano de 1876 e vem sendo amplamente utilizada até os dias atuais. A CDD já passou por várias atualizações, estando hoje em sua 23a edição, trata-se de um sistema estruturado hierarquicamente com o uso de números, na ordem decimal, com dez classes principais de assuntos (com notações que vão de 000 a 999). Cada classe principal possui subclasses de assuntos em hierarquia, abrangendo as áreas do conhecimento. 0 sistema de Classificação de Dewey serviu de base para os belgas Henri La Fontaine (1854-1943) e Paul Otlet (1868-1944) na criação da Classificação Decimal Universal, (CDU) que teve sua primeira edição em 1905. A CDD e a CDU são esquemas de classificação hierárquicos de assuntos que, desde sua criação, foram e continuam sendo amplamente usados na organização de acervos e catálogos de bibliotecas ao redor do mundo, tanto os físicos como digitais.

É interessante notar que, fora dos acervos de bibliotecas, os recursos de arranjos ou esquemas de classificação em formato de hierarquia podem ser frequentemente observados, hoje em dia, na organização da informação em diversos websites de pesquisa. Eles podem aparecer de forma visível, ajudando os usuários na interface de pesquisa ou serem usados na estrutura interna do site, auxiliando na organização de diferentes tipos de conteúdos (ROSENFELD; MORVILLE; ARANGO, 2015). Sobre o uso de relacionamentos hierárquicos em sites, Rosenfeld, Morville e Arango (2015) acrescentam que desenvolver hieraquias não é uma tarefa tão fácil quanto parece. 
Um exemplo do uso de estruturas com relacionamento hierárquico pode ser observado no site de Atlas Escolar do Instituto Brasileiro de Geografia e Estatística - IBGE. A figura 6, a seguir, mostra que o IBGE classificou e organizou os mapas do Brasil e do mundo em diferentes tipos de categorias hierarquizadas no website.

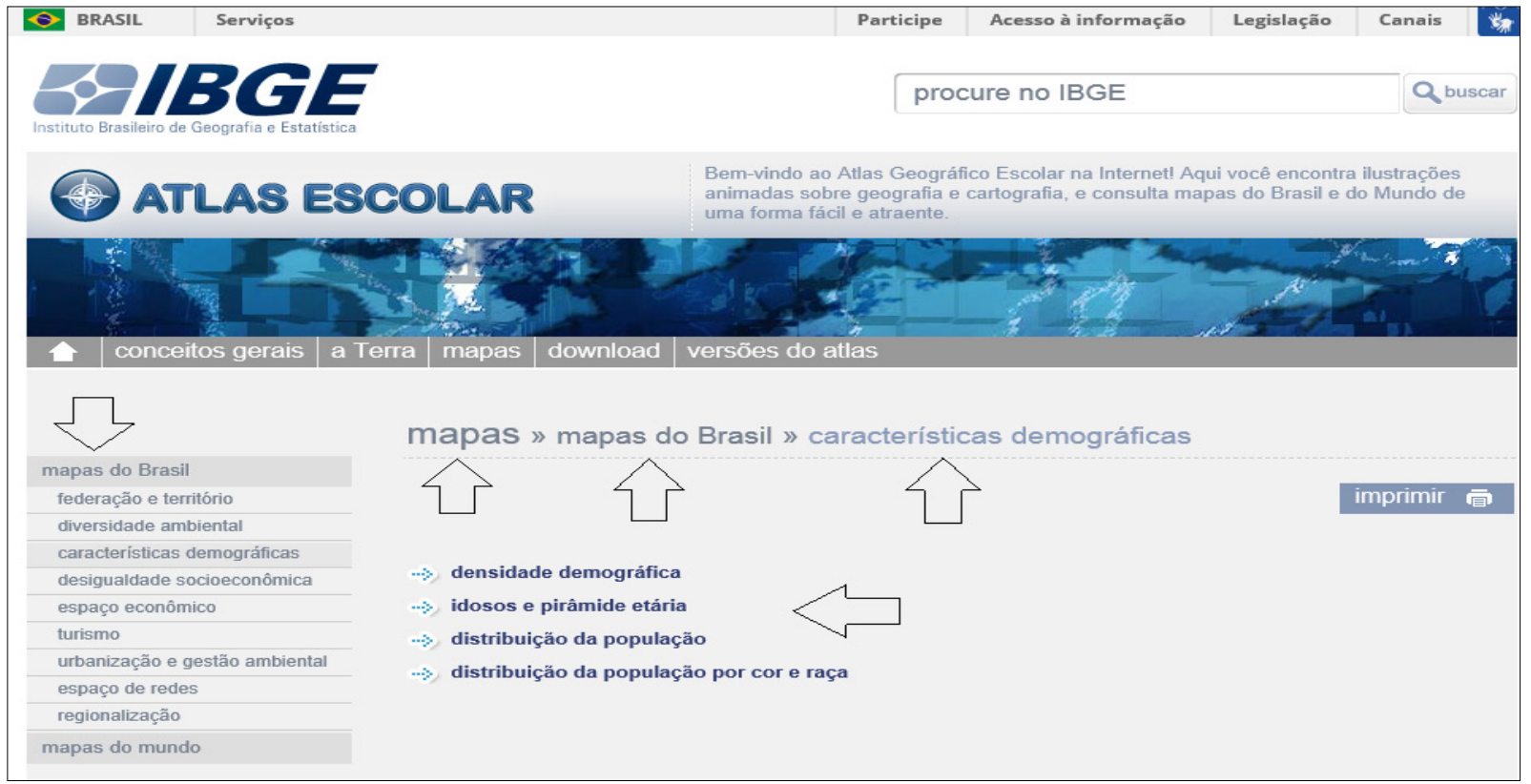

Figura 6 - Organização de mapas a partir de diferentes categorias e subcategorias no site do IBGE Fonte: Disponível em <http://atlasescolar.ibge.gov.br/mapas-atlas>. Acesso em: 04 ago. 2017.

Além das estruturas em hierarquias únicas de cima para baixo, um outro tipo de classificação facilmente encontrada em diversos websites é a classificação facetada, que permite hierarquias múltiplas. A classificação facetada foi inserida no universo da organização da informação pelo bibliotecário indiano Shialy Rammarita Ranganathan (1897-1972) na década de 1930. Ranganathan, reconheceu a rigidez das classificações decimais hierárquicas e criou um sistema mais flexível considerando que documentos e objetos têm múltiplas dimensões (CAMPOS, 2001; ROSENFELD; MORVILLE; ARANGO, 2015). Sobre a teoria desenvolvida por Ranganathan, acerca da classificação facetada, Duarte (2010, p. 48) afirma que,

Trata-se então, de uma fragmentação de um assunto completo em facetas (partes constituintes) por meio de categorias fundamentais denominadas PMEST (Personalidade, Matéria, Energia, Espaço, Tempo). Nesta teoria Personalidade é a característica que distingue um assunto. Matéria é o material físico do qual um assunto pode ser composto. Energia ação que ocorre em torno de um assunto. Espaço é o componente geográfico da localização de um assunto. Já Tempo tratase do período associado com um assunto.

Para Rosenfeld, Morville e Arango (2015), no atual mundo dos negócios, no lugar das facetas universais propostas por Ranganatham (Personalidade, Matéria, Energia, Espaço, Tempo), o que vemos hoje na web são as seguintes facetas principais: Tema, Produtos, Tipo de documento, Público, Geografia e Preço. Segundo os autores, a classificação facetada e as hierarquias múltiplas permitem disponibilizar as informações em mais de uma maneira, isto faz com que as pessoas encontrem suas próprias rotas para as coisas que estão procurando.

\subsection{OS TESAUROS}

No âmbito da CI, o Tesauro pode ser definido como um conjunto de termos ou um vocabulário controlado de uma determinada área do conhecimento, "formalmente organizado para explicitar as relações a priori entre conceitos (por exemplo, como genéricas e específicas)" (UNESCO, 1993, p. 14). Os primeiros tesauros "foram desenvolvidos para bibliotecas, museus e agências governamentais muito antes da invenção da World Wide Web" (ROSENFELD; MORVILLE; ARANGO, 2015, p. 270, tradução nossa). 0 termo tesauro começou a ser utilizado na esfera da CI a partir da década de 1940 "como sendo um instrumento capaz de transportar conceitos e suas relações mútuas [...]” (DODEBEI, 2002, p. 66). 
O tesauro é considerado um tipo mais sofisticado de controle de vocabulário e se diferencia dos demais, tais como os anéis sinônimos e os registros de autoridades, pelo seu nível de complexidade e por abranger uma maior variedade de relacionamentos semânticos entre os termos que representam os assuntos (ROSENFELD; MORVILLE; ARANGO, 2015). A construção de um tesauro não é uma tarefa simples, envolve uma série de estudos aprofundados sobre áreas do conhecimento e a observação de normas e diretrizes reconhecidas internacionalmente.

Ao contrário de uma lista simples de termos aprovados, um tesauro também documentará termos alternativos que são comumente usados, mas não aprovados para uso no site. [...] Um tesauro também pode incluir outros tipos de relações entre os termos, fornecendo recomendações para termos mais amplos, mais específicos ou relacionados. Documentar esses relacionamentos pode darlhe uma imagem mais completa de toda a gama de conceitos encontrados em seu conteúdo, o que, por sua vez, pode sugerir abordagens arquitetônicas adicionais (GARRET, 2011, p. 99, tradução nossa).

De acordo com Lima e Maculan (2017, p. 65), "as relações semânticas estabelecidas em um tesauro são, basicamente: (a) hierárquicas (gênero-espécie; todo-parte); (b) de equivalência (sinônimos); (c) associativas (ligações semânticas)". Além dos relacionamentos semânticos, os termos de um tesauro podem conter notas explicativas com informações sobre o significado do termo, sobre a data da criação do termo, instruções para indexadores e outras (UNESCO, 1993, p. 31). No Quadro 2, a seguir, foram listados os principais componentes da estrutura dos termos de um tesauro:

Quadro 2: Componentes da estrutura de um termo no Tesauro.

\begin{tabular}{|l|l|}
\hline \multicolumn{1}{|c|}{ Principais componentes } & \multicolumn{1}{c|}{ Detalhes estruturais } \\
\hline $\begin{array}{l}\text { Relacionamentos de } \\
\text { Equivalência }\end{array}$ & $\begin{array}{l}\text { Um termo preferido é ligado a sinônimos e/ou quase-sinônimos por meio de } \\
\text { remissivas expressas pelas abreviaturas USE e UP “usado para" }\end{array}$ \\
\hline $\begin{array}{l}\text { Relacionamentos } \\
\text { Hierárquicos }\end{array}$ & $\begin{array}{l}\text { Ligações de um termo preferencial Termos Genéricos, (expressos pela } \\
\text { abreviatura TG) ou com Termo mais Específico (TE), dentro da mesma } \\
\text { hierarquia de assuntos. }\end{array}$ \\
\hline Relacionamentos Associativos & $\begin{array}{l}\text { Associação entre termos de diferentes hierarquias por meio da ligação de um } \\
\text { termo a outros Termos Relacionados (TR) ou (TA=termo associado) }\end{array}$ \\
\hline Notas & $\begin{array}{l}\text { As notas de escopo ou Notas Explicativas (expressas pela abreviatura NE), } \\
\text { explicam melhor alguns conceitos ou dão orientações quanto ao seu uso. }\end{array}$ \\
\hline
\end{tabular}

Fonte: Elaborado a partir de Lancaster (1987) e Gomes (1984).

Atualmente, é possível encontrar tesauros de diversas áreas do conhecimento, com suas terminologias prontas, disponíveis para consulta na web, citando apenas alguns, pode-se mencionar: o Tesauro de Folclore e Cultura Popular Brasileira (disponível em: http://www.cnfcp.gov.br/tesauro); o Tesauro Brasileiro de Ciência da Informação (disponível em http://www.ibict.br) e o Nasa Thesaurus (https://www.sti.nasa.gov/nasa-thesaurus). Entretanto, um exemplo interessante de um tesauro em pleno funcionamento na web pode ser observado no site do Instituto Nacional de Estudos e Pesquisa Educacionais Anísio Teixeira - INEP. O INEP disponibiliza não somente a visualização das terminologias na área da Educação, mas também o acesso e a pesquisa em documentos indexados, por meio da busca por assuntos no tesauro on-line (disponível em: http://portal.inep.gov.br/thesaurus-brasileiro-da-educacao).

Ao destacar a importância dos tesauros nos processos de informação, Currás (2010) aponta que, apesar dos avanços da computação e de sistemas especializados facilitarem os processos de busca pela informação, o interesse nos tesauros não tem diminuído visto que os desenvolvedores de softwares "certamente têm que saber como estabelecer relações entre termos e coordenar conceitos. 0 trabalho intelectual não é feito por máquinas, mas por seres humanos” (CURRÁS, 2010, p. 65, tradução nossa).

Para que os vocabulários controlados, os registros de autoridades e os tesauros funcionem bem em um ambiente digital, é muito importante que se adote o uso adequado de padrões de metadados.

\section{ESTRUTURAS DE REPRESENTAÇÃO DA INFORMAÇÃO: OS METADADOS}

Os metadados, muitas vezes são definidos, na literatura, como sendo dados sobre dados, em outros casos o termo pode ser usado para designar informação legível por máquina, entretanto, essas definições mostram-se muito vagas diante da importância de tais recursos, hoje, na web. Para Lima, Santos e Santarém Segundo (2016, p. 52), "metadados é um termo genérico que abrange uma ampla variedade de tipos específicos de informações, as quais são criadas ou capturadas sob vários tipos de recursos informacionais" e podem conter informações que mostram como, quando e por quem o recurso foi armazenado. 
Muitas empresas hoje estão usando metadados de maneiras mais sofisticadas. Aproveitando o software de gerenciamento de conteúdo e os vocabulários controlados, eles criam sistemas dinâmicos orientados a metadados que suportam a criação distribuída e a navegação poderosa. (ROSENFELD; MORVILLE; ARANGO, 2015, p. 271, tradução nossa)

Em outras palavras, os metadados são utilizados para estruturar de forma organizada os conteúdos informacionais de modo a facilitar a recuperação das informações. Outrossim, os metadados não são uma novidade para os bibliotecários e os profissionais da informação visto que estes já os utilizam há muito tempo, na prática da representação descritiva e da representação temática de materiais em acervos, sejam digitais ou não. Antes da era digital, o registro dos dados era realizado por meio de fichas ou cartões impressos que eram armazenados e possibilitavam buscas manuais. Com o avanço tecnológico surgiu a necessidade de transportar essas fichas para os sistemas de recuperação da informação tendo seus dados estruturados de forma legível por computador, para tal, as bibliotecas começaram a utilizar os padrões de metadados. Os padrões (ou formatos) de metadados são emitidos por agências de normas e outras organizações, tais como: International Organization for Standardization (ISO), the Library of Congress (LC), the Getty Research, the Wide Web Consortium (W3C), entre outros. (LIMA; SANTOS; SANTARÉM SEGUNDO, 2016, p. 54). Alguns exemplos de padrões de metadados muito utilizados atualmente, são: Machine Readable Cataloging (MARC) usado para recursos bibliográficos; Metadado Brasileiro para Teses e Dissertações (MTDBR), e Dublin Core (DC).

Assumpção e Santos (2015) destacam o Formato MARC, que é um conjunto de padrões de metadados que teve sua origem na década de 1960 e que é muito utilizado até os dias atuais em catálogos de biblioteca, para a descrição bibliográfica dos materiais e, também para controle de vocabulários e autoridades. No presente estudo, o uso do padrão MARC foi observado, por exemplo, no catálogo online da BN tornando possível a organização dos dados de descrição bibliográfica, conforme demonstrado anteriormente nas Figuras 2 e 5.

De acordo com Castro e Santos (2014, p. 21) "com o registro de metadados a capacidade de interoperabilidade aumenta, assim como a precisão de qualquer compartilhamento de elemento de dados e vocabulários". E acrescentam:

0 uso dos modelos conceituais de dados, das arquiteturas de metadados e das ontologias redesenham os novos ambientes informacionais digitais, definindo conceitualmente os elementos da descrição bibliográfica a serem representados pelo catalogador, proporcionando interfaces de buscas mais compreensíveis aos usuários e no estabelecimento efetivo da interoperabilidade (CASTRO; SANTOS, 2014, p. 23)

Dessa forma, é possível concluir que, além de contribuir para organização e a recuperação de informações, uma outra característica importante dos metadados é a sua capacidade de interoperabilidade, incluindo a possibilidade de realização de intercâmbios de dados entre diferentes instituições.

\section{CONSIDERAÇÕES FINAIS}

A Arquitetura da Informação compreende os sistemas de Organização, Rotulação, Navegação e Busca. Para que um website tenha usabilidade, esses sistemas precisam interagir e devem estar apoiados pelas Estruturas de Representação da Informação, que são: os vocabulários controlados, os tesauros e os metadados (ROSENFELD; MORVILLE; ARANGO, 2015). Com a presente pesquisa, foi possível identificar características desses instrumentos de representação da informação originalmente e comumente utilizados nos trabalhos dos profissionais da informação e que agora, na era digital, se fazem muito presentes também na arquitetura dos websites.

Dentre as características observadas nos sites consultados, destacaram-se nesta pesquisa: a) os controles simples de termos e vocabulários por meio de mapeamento de sinônimos ou termos equivalentes; b) as categorias de temas/assuntos em hierarquia única, do maior para o menor, princípio advindo dos Esquemas de Classificação, originalmente utilizados na organização de bibliotecas e arquivos; c) a representação de conteúdos em facetas ou categorias múltiplas de assuntos/temas que guiam o usuário na pesquisa; d) o uso de registros de autoridade com o emprego de hiperlinks para promover mobilidade na pesquisa, em diferentes tipos de categorias (por assunto, por nome, etc); e) os tesauros em ambientes digitais permitindo a organização e a busca de materiais bibliográficos por assunto/tema, em áreas do conhecimento específicas. Além disso, nos bastidores da organização da informação, estão os padrões de metadados como peças importantes para tornar todo esse controle possível. Diante da enormidade de conteúdos informacionais criados e disponibilizados na internet diariamente, a tendência aponta para um avanço nos tipos, nos formatos e no uso dessas importantes estruturas de representação da informação. 


\section{REFERÊNCIAS:}

ASSUMPÇÃO, Fabrício Silva; SANTOS, Plácida Leopoldina Ventura Amorim da Costa. Metadata Authority Description Schema (MADS): uma alternativa à utilização do formato MARC 21 para dados de autoridade. Inf. Inf., Londrina, v. 18, n.1, p. 106 - 126, jan./abr. 2013. Disponível em: $<$ http://www.uelbr/revistas/uel/index.php/informacao/article/view/12293/pdf>. Acesso em: 13 ago. 2017.

ASSUMPÇÃO, Fabrício Silva; SANTOS, Plácida Leopoldina Ventura Amorim da Costa. Representação no domínio bibliográfico: um olhar sobre os Formatos MARC 21. Perspectivas em Ciência da Informação, v.20, n.1, p.54-74, jan./mar. 2015. Disponível em:

$<$ http://portaldeperiodicos.eci.ufmg.br/index.php/pci/article/view/2054>. Acesso em: 13 ago. 2017.

CAMPOS, Maria Luiza de Almeida. Linguagem Documentária: teorias que fundamentam sua elaboração. Rio de Janeiro: EdUFF, 2001.

CASTRO, Fabiano Ferreira de; SANTOS, Plácida Leopoldina Ventura Amorim da Costa. Os metadados como instrumentos tecnológicos na padronização e potencialização dos recursos informacionais no âmbito das bibliotecas digitais na era da web semântica. Inf. \& Soc.: Est., João Pessoa, v.17, n.2, p.13-19, maio/ago. 2007. Disponível em: <http://www.periodicos.ufpb.br/ojs/index.php/ies/article/view/840/1442>. Acesso em: 05 ago. 2017.

CASTRO, Fabiano Ferreira de; SANTOS, Plácida Leopoldina Ventura Amorim da Costa. Elementos de interoperabilidade na perspectiva da catalogação descritiva. Inf. \& Soc.: Est., João Pessoa, v.24, n.3, p. 13-25, set./dez. 2014. Disponível em: <http://www.periodicos.ufpb.br/ojs/index.php/ies/article/view/16660>. Acesso em: 05 ago. 2017.

CATARINO, Maria Elisabete; CERVANTES, Brígida Maria Nogueira; ANDRADE, Ilza Almeida de. A representação temática no contexto da web semântica. Inf. \& Soc.: Est., João Pessoa, v.25, n.3, p. 105-116, set./dez. 2015. Disponível em:

$<$ http://www.periodicos.ufpb.br/ojs/index.php/ies/article/view/16242/14531>. Acesso em: 05 ago. 2017.

CATARINO, Maria Elisabete; SOUZA, Terezinha Batista de. A representação descritiva no contexto da web semântica. TransInformação, Campinas, 24(2):77-90, maio/ago., 2012. Disponível em: $<$ http://www.scielo.br/scielo.php?script=sci arttext\&pid=S0103-37862012000200001>. Acesso em: 20 ago. 2018.

CURRÁS, Emilia. Ontologies, Taxonomies and Thesauri in Systems Science and Systematics. Oxford: Chandos Publishing, 2010.133 p. Disponível em: < http://livroaberto.ibict.br>. Acesso em 09 jul. 2018.

DODEBEI, Vera Lucia Doyle. Tesauro: linguagem de representação da memória documentária. Rio de Janeiro: Interciência, 2002. $120 \mathrm{p}$.

DUARTE, Elizabeth Andrade. Classificação facetada: um olhar sobre a construção de estruturas semânticas. Revista Digital de Biblioteconomia e Ciência da Informação, Campinas, v.7, n. 2, p. 46-58, jan./jun. 2010. Disponível em: <https://periodicos.sbu.unicamp.br/ojs/index.php/rdbci/article/view/1956>. Acesso em: 06 ago. 2017.

FERREIRA, Luciene da Costa; ALBUQUERQUE, Maria Elizabeth Baltar Carneiro de. A representação da informação para a organização do acervo em bibliotecas universitárias. In: ALBUQUERQUE, Maria Elizabeth Baltar Carneiro de et al (Org.). Representação da informação: um universo multifacetado. João Pessoa: Editora da UFPB, 2013. Cap.1. p.15-28.

GARRET, Jesse James. The elements of user experience: user-centered design for the web and beyond. 2. ed. Berkeley, CA: News Riders, 2011.

GOMES, Hagar Espanha (Coord). Instituto brasileiro de informação em ciência e tecnologia - IBICT. Diretrizes para elaboração de tesauros monolíngues. Brasília: IBICT, 1984. 70 p. 
GOMES, Henriette Ferreira; SANTOS, Raquel do Rosário. Representação e organização da informação científica como ações de mediação implícita: compromisso da biblioteca universitária com o ethos da ciência e a afiliação acadêmica. In: ALBUQUERQUE, M. E. B. C. et al (Org.). Representação da informação: um universo multifacetado. João Pessoa: Editora da UFPB, 2013.

GRINGS, Luciana. Controle de autoridades na Biblioteca Nacional do Brasil: breve histórico e práticas atuais. Revista Brasileira de Biblioteconomia e Documentação. São Paulo, v. 11, n. 2, p. 139-154, jul./dez. 2015. Disponível em: <https://rbbd.febab.org.br/rbbd/article/view/433>. Acesso em: 06 ago. 2017.

LANCASTER, Frederick Wilfrid. Construção e uso de tesauros: curso condensado. Brasília: IBICT, 1987.

LIMA, Fábio Rogério Batista; SANTOS, Plácida Leopoldina V. A. C.; SANTARÉM SEGUNDO, José Eduardo. Padrão de metadados no domínio museológico. Perspectivas em Ciência da Informação, v.21, n.3, p.50-69, jul./set. 2016. Disponível em: < http://portaldeperiodicos.eci.ufmg.br/index.php/pci/article/view/2639>. Acesso em: 06 ago. 2017.

LIMA, Gercina Ângela de; MACULAN, Benildes Coura Moreira dos Santos. Estudo comparativo das estruturas semânticas em diferentes sistemas de organização do conhecimento. Ciência da Informação, [S.I.], v. 46, n. 1, dez. 2017. Disponível em: <http://revista.ibict.br/ciinf/article/view/4014>. Acesso em: 06 jul 2018.

MAIA, Manuela Eugênio et al. Análise sobre sistemas de busca na perspectiva da arquitetura da informação em ambiente de cordéis. Biblos: Revista do Instituto de Ciências Humanas e da Informação, v. 29, n.2, 2015. Disponível em: <https://www.seer.furg.br/biblos/article/view/5506>. Acesso em: 05 ago. 2017.

ROSENFELD, Louis; MORVILLE, Peter; ARANGO, Jorge. Information architecture for the web and beyond. 4. ed. Sebastopol, CA: O’Relly Media, 2015.

SAMPIERI, Roberto Hernandez; COLLADO, Carlos Fernández; LUCIO, Maríadel Pilar Baptista. Metodologia da pesquisa. 3. ed. São Paulo: McGraw-Hill, 2006.

SILVA, Márcio Bezerra da; NEVES, Dulce Amélia de Brito. A aplicação da teoria facetada em banco de dados, através da modelagem conceitual. In: ALBUQUERQUE, Maria Elizabeth Baltar Carneiro de et al (Org.).

Representação da informação: um universo multifacetado. João Pessoa: Editora da UFPB, 2013. p.237-262.

SILVA, Maria Amélia Teixeira da; DIAS, Guilherme Ataíde; SOUSA, Marckson Roberto Ferreira de. Arquitetura da informação em ambientes informacionais: uma epistemologia sob a perspectiva de Paul Otlet. In: MOTA, Ana Roberta Sousa et al (Org.). Versados em Ciência da Informação. João Pessoa: Imprell, 2014. Cap. 11. p. 229-248.

SILVA, Zayr Claudio Gomes da; SOUZA, Edivanio Duarte de. Indicadores da produção colaborativa na arquitetura da informação. Rev. Digit. Bibliotecon. Cienc. Inf. Campinas, SP, v.15, n.2, p. 368-388, maio/ago 2017. Disponível em: <https://periodicos.sbu.unicamp.br/ojs/index.php/rdbci/article/view/8647357>. Acesso em: 17 ago. 2017.

SOUSA, Marckson Roberto Ferreira de. 0 acesso a informações e a contribuição da arquitetura da informação, usabilidade e acessibilidade. Inf. \& Soc.: Est., João Pessoa, v.22, p. 65-76, Número Especial 2012. Disponível em: <www.periodicos.ufpb.br/ojs/index.php/ies/article/view/13298/8210>. Acesso em: 27 ago. 2018.

UNESCO. Diretrizes para o estabelecimento e desenvolvimento de tesauros monolíngues. [ $2^{\mathrm{a}}$ ed. rev. por Derek Austin e Peter Dale]; traduzido por Bianca Amaro de Meto e revisto por Lígia Maria Café de Miranda. Brasília: IBICT/SENAI, 1993. 86 p. Disponível em: <http://livroaberto.ibict.br>. Acesso em 17 ago. 2017.

Editores do artigo: Enrique Muriel-Torrado, Edgar Bisset Alvarez, Camila Barros. 